\title{
Tartrate-resistant acid phosphate as biomarker of bone turnover over the lifespan and different physiologic stages in sheep
}

José A. Camassa ${ }^{1}$, Camila C. Diogo ${ }^{1}$, João P. A. Bordelo ${ }^{1}$, Marília de A. Bonelli², Carlos A. Viegas ${ }^{1,3}$, Jorge T. Azevedo ${ }^{4,5}$, Nuno Dourado ${ }^{6}$ and Isabel R. Dias ${ }^{1,3^{*}}$

\begin{abstract}
Background: Currently, the best resources for assessment of bone tissue using imaging techniques are expensive and available in few medical facilities, thus serum or urinary bone turnover biomarkers could be useful as early indicators of prognosis. However, there is a wide range of variability in bone turnover markers due to several factors, such as different ages and metabolic stages, thus it is important to have as much data published on the subject as possible. The aim of this study was therefore to generate a reference range for alkaline phosphatase (ALP) and tartrate-resistant acid phosphatase (TRAP) and validate the already published data.

Results: Serum alkaline phosphatase decreased with age, with statistical difference between the 1 month old and the other groups and between the over 8 years and the 6 months old groups. There was also a statistical difference in the ALP levels between the 3 to 5 years old gestation and lactation groups. For serum tartrate-resistant acid phosphatase, there was a statistical difference mainly between the 1 month old and the 6 months old, 6-8 years old, and above 8 years old groups.

Conclusions: The results obtained could represent a useful tool for future studies using sheep as an animal model for orthopedic research. The different groups presented a wide variation of serum ALP and TRAP levels, however, these variations are entirely explained by known physiology. Therefore, this detailed study confirms the prediction that unexplained changes in these bone turnover markers do not occur during the lifespan of sheep.
\end{abstract}

Keywords: ALP, Bone tissue, Serum minerals, Sheep, Tartrate-resistant acid phosphatase

\section{Background}

Currently, skeletal and bone tissue assessment is performed by diagnostic imaging such as radiography, computed tomography, magnetic resonance and densitometry techniques, or invasive methods, such as bone biopsy, although these methods are still limited in many situations. Therefore, determination of the serum levels or urinary bone turnover biomarkers (BTMs) could

\footnotetext{
* Correspondence: idias@utad.pt

'Department of Veterinary Sciences, Agricultural and Veterinary Sciences School (ECAV), University of Trás-os-Montes and Alto Douro (UTAD), Quinta de Prados, P.O. Box 1013, 5001-801 Vila Real, Portugal

${ }^{3} \mathrm{CITAB}$ - Centre for the Research and Technology of Agro-Environmental and Biological Sciences, UTAD, Vila Real, Portugal

Full list of author information is available at the end of the article
}

be a good noninvasive analytical method for evaluation of bone metabolism, as it allows predicting bone cell activity in a quick and real time manner [1].

At present, some studies have been performed on BTMs in animal models for orthopedic research not only to improve the knowledge in animal and veterinary sciences, but also in human orthopedic research of metabolic bone diseases, such as post-menopausal osteoporosis. BTMs could be useful in diagnosing early-stage bone diseases, and helping to monitor evolution and efficiency of treatment.

BTMs are generally divided in two groups: the formation and the bone resorption markers, although there is a third group that is still poorly studied, the osteoclast 
regulatory protein [2]. During the metabolic process of bone formation by osteoblasts, formation markers are represented by serum alkaline phosphatase (ALP) and its bone-specific isoform (BALP), serum osteocalcin, and two other molecules that are released during synthesis of the type I collagen molecule - serum procollagen type I carboxy- and amino-terminal propeptides [3].

The ALP is a glycoprotein that is connected to the surface of cells. In humans ALP are expressed in four gene loci code: nonspecific, intestinal, placental and germ cells [4]. Nonspecific gene is synthesized in a variety of tissues (bone, kidney, liver and early placenta) [4]. BALP has been used due to its high sensitivity as a bone formation marker [4]. It is produced by osteoblasts [5] and is involved in the calcification of bone matrix [6].

In the bone resorption process, there is a breakdown of type I collagen, so resorption markers are represented by serum C-terminal telopeptide of type I collagen, urinary collagen type I cross-linked C- and $\mathrm{N}$-telopeptide, urinary hydroxyproline, total and free urinary pyridinoline and deoxypyridinoline, as well as by the serum tartrateresistant acid phosphatase (TRAP), which is produced by active osteoclasts [7].

TRAP is a glycoprotein produced by mature osteoclasts, activated dendritic cells, and macrophages, therefore TRAP is an indicator of osteoclast and macrophage activity $[8,9]$. There are two known isoforms (TRAP5a,b). TRAP5b is a specific biomarker of osteoclastic resorption activity, while TRAP5a is a non-osteoclastic form [10]. In the future, the latter may be useful in clinical evaluation since it is expressed in bone pathologies, such as fracture healing in different mammals or osteoporosis in women $[9,11,12]$.

The use of sheep as animal models in orthopedic research, also in studies focusing on BTMs, is based on different aspects such as easy handling $[13,14]$ and possibility of blood sample collection several times per day [15] due to a high blood volume when compared to other laboratory animal species. Nevertheless, bone markers in small ruminants are influenced by circadian and seasonal variation [16], among other possible factors causing serum and urinary variability such as diet, exercise, skeletal growth, as well as intra-individual variability [4]. As such, BTMs undergo variations throughout a lifetime, namely with age and different metabolic states. It is therefore important to assess BTMs variation during these phases and establish a reference range for BTMs in this species, to which the greatest limitation is the inter-individual variability [17].

Therefore, the aim of this study was to generate a reference range for some of the main BTMs - ALP and TRAP, throughout the lifespan and different physiological states in sheep and to evaluate possible correlations of these parameters with serum minerals.

\section{Methods}

\section{Animals}

Ninety ewes (Churra-da-Terra-Quente sheep) from the same flock, located in Carrazeda de Ansiães, a municipality in the district of Bragança in northern Portugal were used. Average minimum temperature was $1.9^{\circ} \mathrm{C}$ and average maximum temperature $10.2^{\circ} \mathrm{C}$ in December at Bragança. Sheep were kept in a natural pasture during the day and housed overnight. The barn is easily approachable and spacious, dry, well-drained, well-ventilated and bedding composed by hay and straw. These animals were chosen among a flock according to their age or physiologic state and divided into 9 groups of 10 animals each. The groups were as follows: 1 month old (mean weight $9.3 \mathrm{~kg}$ ), 6 months old (mean weight $22.2 \mathrm{~kg}$ ), 1 year old (mean weight $40.7 \mathrm{~kg}$ ), 2 years old (mean weight $50.2 \mathrm{~kg}$ ), 3 to 5 years old dry (mean weight $52.4 \mathrm{~kg}$ ), 3 to 5 years old with 2 or 3 months of pregnancy (mean weight $55.3 \mathrm{~kg}$ ), 3 to 5 years old with 2 or 3 months of lactation (mean weight $51.5 \mathrm{~kg}$ ), 6 to 8 years old (mean weight $52.1 \mathrm{~kg}$ ), and the last group with animals over 8 years old (mean weight $48.1 \mathrm{~kg}$ ). The diet was composed by grass hay, supplemented with $0.250 \mathrm{~kg}$ of concentrate feed per animal per day and water provided ad libitum. Dry matter and chemical composition of grass hay is made up of dry matter per $\mathrm{kg}$ feed $(88.5 \mathrm{~g})$, ash per kg dry matter $(5.9 \mathrm{~g})$, neutral detergent fiber per $\mathrm{kg}(73.3 \mathrm{~g})$ dry matter and crude protein per $\mathrm{kg}$ dry matter $(6.1 \mathrm{~g})$. Dry matter and chemical composition of feed concentrate is made up of dry matter per $\mathrm{kg}$ feed $(90.4 \mathrm{~g})$, ash per $\mathrm{kg}$ dry matter $(8.5 \mathrm{~g})$, neutral detergent fiber per $\mathrm{kg}(31.6 \mathrm{~g})$ dry matter and crude protein per kg dry matter $(20.7 \mathrm{~g})$.

All animal handling practices followed Directive 2010/ 63/EU of the European Parliament and of the Council on the protection of animals used for scientific purposes.

\section{Blood sampling}

Blood was drawn in December during the European winter. Blood samples were drawn from the jugular vein and placed into serological tubes (S-Monovette, SARSTEDT, Nümbrecht, Germany). Samplings were performed between 9:00 a.m. and 10:00 a.m. and the blood carried in a thermal box to laboratory facilities immediately. Blood was centrifuged (3000 rpm for $10 \mathrm{~min}$ ) and the serum stored in Eppendorf tubes at $-20^{\circ} \mathrm{C}$ until analyses.

\section{Serum biochemical analysis}

Following the manufacturer's instructions, the assays were always performed in duplicate to achieve higher accuracy.

Determination of ALP (Alkaline Phosphatase, Beckman Coulter, Ref. OSR6004, CA, USA) and TRAP (ACP, Ref. 17,617; Sentinel Diagnostics, Milan, Italy) were performed via an enzymatic method and molecular absorption 
spectrophotometry using commercially available kits. Calcium (Ca) (Calcium, Beckman Coulter, Ref. OSR60117, CA, USA), phosphorus (P) (Phosphorus, Beckman Coulter, Ref. OSR6122, CA, USA) and magnesium (Mg) (Magnesium, Beckman Coulter, Ref. OSR6189, CA, USA) were also determined using commercially available kits, via chemical method and molecular absorption spectrophotometry.

\section{Statistical analysis}

Statistical normality was checked using the Shapiro-Wilk W-Test for all groups. Serum BTMs and mineral values are presented as median \pm interquartile range (IQR), minimum (Min) and maximum (Max). Spearman's correlation was obtained between the serum biochemical markers. The Kruskal - Wallis Test was used for testing the nonparametric statistical hypothesis and the Kruskal - Wallis pairwise method for multiple comparisons. Statistical analysis was performed using SPSS software (version 23.0, SPSS, Inc., IBM Company, NY, USA). The level of significance was set at $P<0.05$.

\section{Results}

All parameters in this study revealed a non-normal distribution for age analysis. The median and interquartile range for each marker in different ages are shown in Table 1.

Figure 1a shows a significant difference between the 1 month old group and all the other groups, and a significant difference between animals of 6 months of age and over 8 years for ALP (Fig. 1). For TRAP, the 1 month old and 1 year old groups were the ones with a significant statistical difference from the other groups (Fig. 1b).

Calcium and phosphorus both suffer a slight decrease throughout the animal's life, with a statistical difference seen in the 1 month old and over 8 years old groups for Ca (Fig 1c), and 6 months old and 1 month old groups for P (Fig. 1d), with the latter showing a significant difference when compared to all other groups except the 6 months old group. Magnesium had a slight increase with age (Fig. 1e), with the most significant difference observed between the 1 month old group and the other groups. The degrees of correlation are shown in Table 2. The results expressed a fair correlation between markers, with the highest correlation observed between ALP and P $(r<0.60 ; P<0.01)$.

In the analyses of the groups with animals between 3 and 5 years of age in different physiologic stages, ALP had a significant difference between the gestation and lactation groups (Fig. 2a) and TRAP (Fig. 2b) had a significant difference between the dry and lactation groups. Normality analyses of the groups with 3 to 5 years of age had a normal distribution for $\mathrm{Ca}$ and $\mathrm{P}$ (Fig. 2c and d), ALP, TRAP and Mg (Fig. 2e) had a non-normal
Table 1 Values of serum biochemical markers and serum minerals by ages

\begin{tabular}{|c|c|c|c|}
\hline & & Median \pm IQR & Range \\
\hline & & & (Min-Max) \\
\hline $\mathrm{ALP}(\mathrm{U} / \mathrm{L})$ & 1 month & $849.5 \pm 270.7$ & $520-1354$ \\
\hline & 6 months & $269.5 \pm 136.2$ & $89-454$ \\
\hline & 1 year & $220.0 \pm 135.0$ & $138-583$ \\
\hline & 2 years & $200.5 \pm 90.25$ & $116-295$ \\
\hline & $3-5$ years gestation & $104.5 \pm 116.0$ & $66-350$ \\
\hline & $3-5$ years lactation & $330.5 \pm 159.2$ & 105-390 \\
\hline & $3-5$ years dry & $181.0 \pm 133.5$ & $108-363$ \\
\hline & $6-8$ years & $197.0 \pm 127.0$ & $63-444$ \\
\hline & $>8$ years & $119.0 \pm 177.0$ & $35-277$ \\
\hline TRAP $(U / L)$ & 1 month & $3.15 \pm 0.45$ & $2.9-3.7$ \\
\hline & 6 months & $2.65 \pm 0.10$ & $2.5-2.9$ \\
\hline & 1 year & $3.10 \pm 0.50$ & $2.4-3.6$ \\
\hline & 2 years & $2.95 \pm 0.60$ & $2.2-3.2$ \\
\hline & $3-5$ years gestation & $2.80 \pm 0.25$ & $2.6-3.0$ \\
\hline & $3-5$ years lactation & $2.55 \pm 0.37$ & $2.3-2.8$ \\
\hline & $3-5$ years dry & $2.80 \pm 0.25$ & $2.0-3.3$ \\
\hline & $6-8$ years & $2.50 \pm 0.07$ & $2.4-2.7$ \\
\hline & $>8$ years & $2.65 \pm 0.47$ & $1.6-3.3$ \\
\hline Calcium (mmol/L) & 1 month & $2.83 \pm 0.12$ & $2.57-2.90$ \\
\hline & 6 months & $2.59 \pm 0.23$ & $2.35-2.75$ \\
\hline & 1 year & $2.63 \pm 0.10$ & $2.55-2.83$ \\
\hline & 2 years & $2.53 \pm 0.20$ & $2.33-2.68$ \\
\hline & $3-5$ years gestation & $2.49 \pm 0.16$ & $2.18-2.68$ \\
\hline & $3-5$ years lactation & $2.49 \pm 0.18$ & $2.38-2.65$ \\
\hline & $3-5$ years dry & $2.54 \pm 0.13$ & $2.35-2.65$ \\
\hline & $6-8$ years & $2.61 \pm 0.10$ & $2.50-2.68$ \\
\hline & $>8$ years & $2.33 \pm 0.21$ & $1.85-2.48$ \\
\hline Magnesium (mmol/L) & 1 month & $0.91 \pm 0.07$ & $0.78-1.03$ \\
\hline & 6 months & $0.96 \pm 0.04$ & $0.96-1.04$ \\
\hline & 1 year & $1.02 \pm 0.14$ & $0.92-1.29$ \\
\hline & 2 years & $1.04 \pm 0.09$ & $0.95-1.12$ \\
\hline & $3-5$ years gestation & $1.08 \pm 0.17$ & $0.92-1.29$ \\
\hline & $3-5$ years lactation & $1.03 \pm 0.03$ & $1.02-1.08$ \\
\hline & $3-5$ years dry & $0.97 \pm 0.07$ & $0.93-1.13$ \\
\hline & $6-8$ years & $1.05 \pm 0.13$ & $0.89-1.32$ \\
\hline & $>8$ years & $1.12 \pm 0.26$ & $0.88-1.56$ \\
\hline Phosphorous (mmol/L) & 1 month & $3.21 \pm 0.27$ & $3.10-3.52$ \\
\hline & 6 months & $2.21 \pm 0.53$ & $1.06-2.87$ \\
\hline & 1 year & $1.87 \pm 0.46$ & $1.58-2.29$ \\
\hline & 2 years & $1.59 \pm 0.25$ & $1.23-1.81$ \\
\hline & $3-5$ years gestation & $1.42 \pm 0.63$ & $1.13-1.98$ \\
\hline & $3-5$ years lactation & $1.45 \pm 0.30$ & $1.16-1.81$ \\
\hline & $3-5$ years dry & $1.36 \pm 0.24$ & $0.90-1.90$ \\
\hline & $6-8$ years & $1.56 \pm 0.36$ & $1.10-2.06$ \\
\hline & $>8$ years & $1.64 \pm 0.05$ & $1.06-2.42$ \\
\hline
\end{tabular}

ALP: alkaline phosphatase; TRAP: tartrate-resistant acid phosphatase; IQR: interquartile range; Min: minimum; Max: maximum 
Camassa et al. BMC Veterinary Research (2017) 13:239

Page 4 of 8

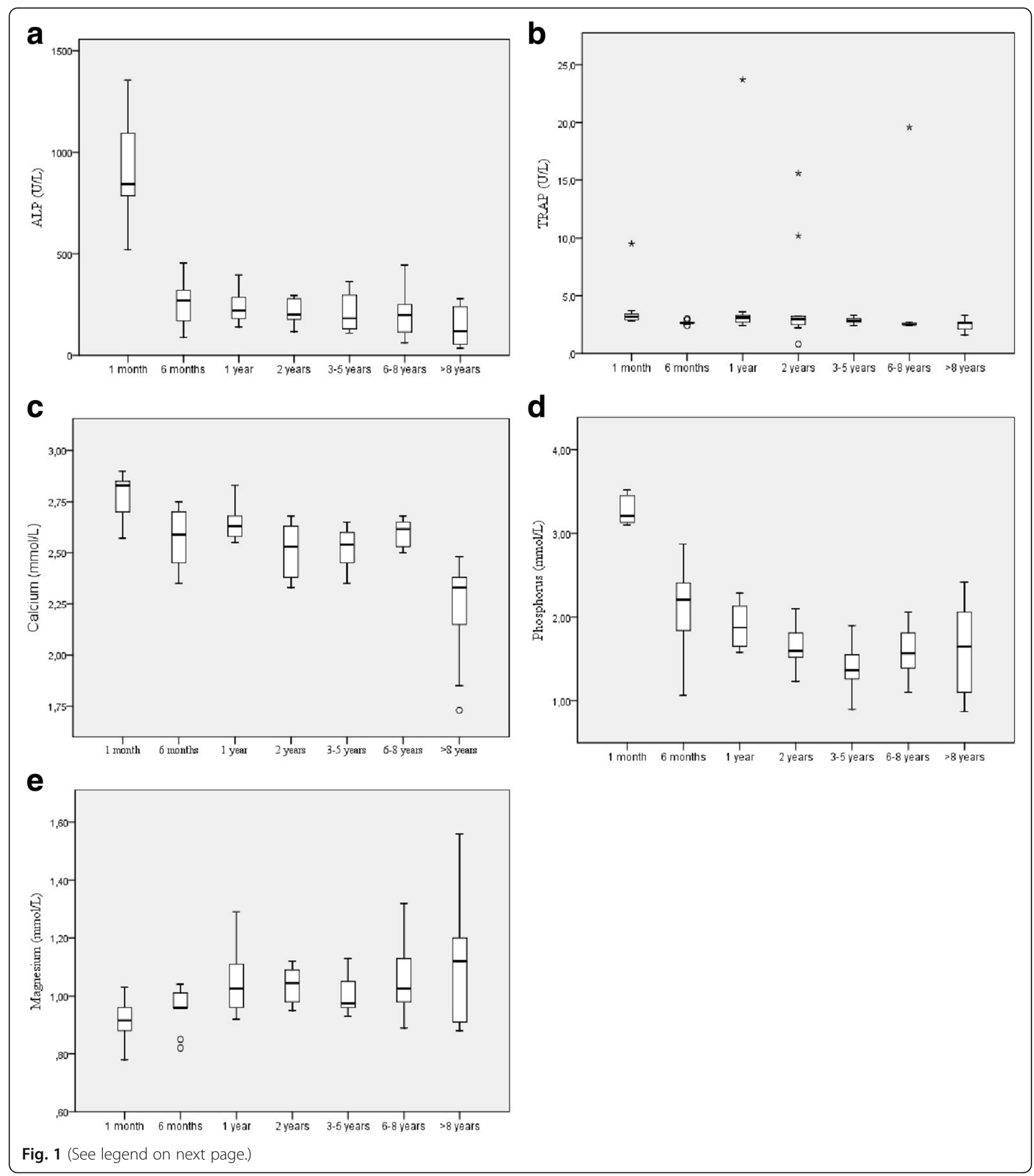


(See figure on previous page.)

Fig. 1 Box plot presentations of serum concentrations of biomarkers of bone metabolism by age. a Serum ALP activity presented significant difference between 1 month vs. 6 months $(P<0.01)$, between 1 month vs. 1 year, 2 years, $3-5$ years, $6-8$ years and $>8$ years $(P<0.001)$, between 6 months vs. $>8$ years $(P<0.05)$. $\mathbf{b}$ Serum TRAP activity presented significant difference between 1 month vs. 6 months, $>8$ years $(P<0.01)$, between 1 month vs. 6-8 years $(P<0.001)$, between 1 year vs. 6 months, $>8$ years $(P<0.05)$, between 1 year vs. $6-8$ years $(P<0.01)$, between 2 years vs. $6-8$ years $(P<0.05)$. c Serum calcium activity presented significant difference between 1 month vs. 6 months, $6-8$ years $(P<0.05)$, between 1 month vs. 2 years and $3-5$ years $(P<0.01)$, between 1 month vs. $>8$ years $(P<0.001)$, between $>8$ years vs. 2 years and $3-5$ years $(P<0.05)$, between $>8$ years vs. 6 month and $6-8$ years $(P<0.01)$ and between $>8$ years vs. 1 year $(P<0.001)$. $\mathbf{d}$ Serum ALP activity presented significant difference between 1 month vs. 6 months $(P<0.05)$, between 1 month vs. 1 year $(P<0.01)$, between 1 month vs. 2 years, $3-5$ years, $6-8$ years and $>8$ years $(P<0.001)$, between 6 months vs. 2 years, $3-5$ years, $6-8$ years and $>8$ years $(P<0.05)$ and between 1 year vs. $3-5$ year $(P<0.05)$. e Serum Magnesium activity presented significant difference between 1 month vs. $3-5$ years $(P<0.05)$ and between 1 month vs. 1 year, 2 years, $6-8$ years and $>8$ years $(P<0.01)$. Outliers are identified with small circle for out values and star for extreme values

distribution. Correlation between the three groups did not reveal a statistically significant difference.

\section{Discussion}

The aim of this study was to assess the behavior of serum ALP, TRAP, and minerals in different ages and physiologic stages of the ewes life, therefore providing a dataset and information to assist in research studies focusing on BTMs in sheep.

In this study, the median ALP value was within the normal range reported for this species (68-387 U/L) [18] and the variations over the lifespan in sheep can explained by physiological changes. The interval range was wide, however, possibly due to such factors as seasonal influence, with decreased formation marker (BALP) during Autumn [16], or circadian influence, in which there is a variation of bone markers throughout the day. Because of the latter, blood samples sampling must be drawn at a standardized time [15]. Age was another influencing factor, with a higher level of ALP found in 1-month old animals, possibly due to synthesis in a variety of tissues, not only due to the bone isoenzyme [4], and high juvenile metabolism [19]. Lower levels of ALP were found in sheep over 8 years of age, possibly due to the influence of age in decreasing bone formation. In another study, Haversian remodelling in the caudal aspect of the femur, diaphysis of the radius and humerus was observed in sheep between 7 and 9 years of age [20], which justifies a link between advanced age and bone loss.

Table 2 Correlation between serum biochemical markers and serum minerals

\begin{tabular}{llllll}
\hline & ALP & TRAP & Ca & P & Mg \\
\hline ALP & - & $r=0.44^{\mathrm{b}}$ & $r=0.514^{\mathrm{b}}$ & $r=0.581^{\mathrm{b}}$ & $r=0.229$ \\
TRAP & - & - & $r=0.379^{\mathrm{b}}$ & $r=0.261^{\mathrm{a}}$ & $r=-0.066$ \\
$\mathrm{Ca}$ & - & - & - & $r=0.492^{\mathrm{b}}$ & $r=-0.322^{\mathrm{b}}$ \\
$\mathrm{P}$ & - & - & - & - & $r=-0.289^{\mathrm{a}}$ \\
$\mathrm{Mg}$ & - & - & - & - & - \\
\hline
\end{tabular}

${ }^{a}$ correlation coefficient is significant at the 0.05 level

${ }^{\mathrm{b}}$ correlation coefficient is significant at the 0.01 level
Previously reported values for $\mathrm{P}(1.62-3.36 \mathrm{mmol} / \mathrm{L})$ and $\mathrm{Mg}(0.9-1.31 \mathrm{mmol} / \mathrm{L})$ [18] were within the interval found in the present study, although Ca levels (2.88$3.2 \mathrm{mmol} / \mathrm{L}$ ) [18] were higher in the aforementioned paper. This Ca value could be caused by a decrease in this mineral in pasture, as previously described [21]. In the referred works the lowest value of $\mathrm{Ca}$ was found in different samples from different grazing areas during Winter. Blood samples in the present study were drawn in the same season, however, pasture analyses were not performed which renders impossible to investigate a correlation.

In general, for serum minerals, there was a significant difference between the 1 month old group and the other groups, possibly due to the high bone modelling process that is occurring at this age. In fact, as the skeletal structure in these animals is still in growth, there is an increasing demand for $\mathrm{Ca}$ and $\mathrm{P}$ [22]. A statistical difference in serum minerals between 1-month-old and 6-months-old groups was not expected since both groups have growing animals. There was, however, a statistical difference in $\mathrm{Ca}$ and $\mathrm{P}$ between the two groups, possibly due to a change in feed, with the absence of milk and a diet based on grass and concentrate at 6 months old. The decrease in $\mathrm{Ca}$ in animals over 8 years of age when compared to the other groups may be associated with bone remodelling in older sheep, as has been reported [20], where the decline in $\mathrm{Ca}$ would thus be expected due to a decrease in bone mineralization.

During the analysis of the TRAP marker, the 1-month old animals had a higher range interval, probably related to an accelerated resorption during skeletal growth [9]. However, 6-months-old animals had a low level of this marker even though the sheep were undergoing skeletal growth, possibly because of a difference in diet, as previously mentioned. This marker showed an inversely proportional relationship with age, thus the animals with 6 to 8 years of age had lower values among all the groups. However, those over 8 years old had an increased TRAP, possibly due to osteoclastic activity [9] in geriatric animals. An explanation for this increase has not been investigated in this study in older sheep. Nevertheless, in older women, it is associated to osteoporosis [23]. Therefore, there may 

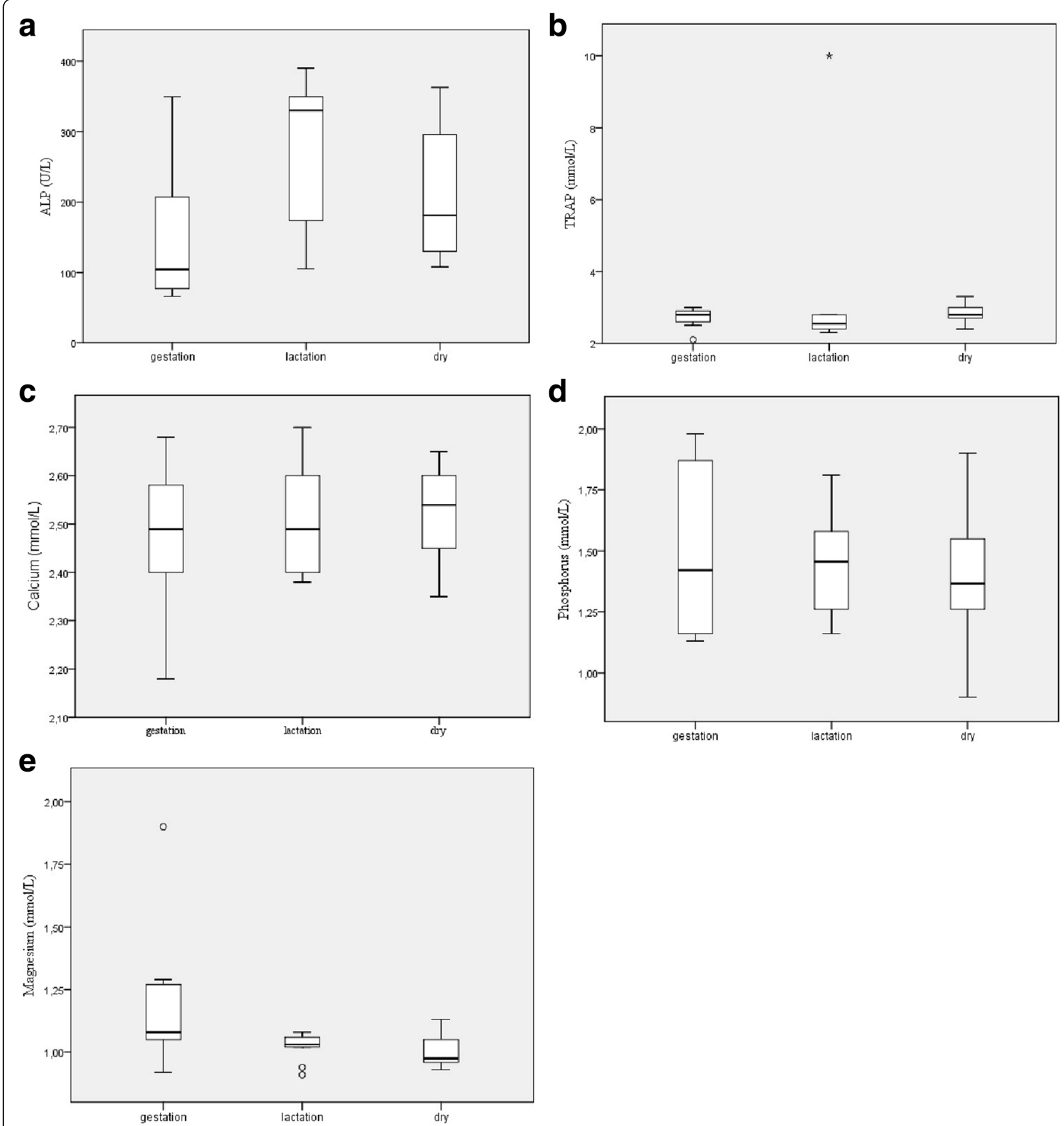

Fig. 2 Box plot presentations of serum concentrations of biomarkers of bone metabolism by physiologic stages. a Serum ALP activity presented significant difference between gestation vs. lactation $(P<0.05)$. b Serum TRAP activity, there was no significant difference between the groups. c Serum Calcium activity, there was no significant difference between the groups. d Serum Phosphorus activity, there was no significant difference between the groups. e Serum Magnesium activity, there was no significant difference between the groups. Outliers are identified with small circle for out values and star for extreme values

be an osteopenia in old animals related to an increase of this marker, but analyses of the bone, such as bone densitometry, would be necessary to prove that.

It should also be mentioned that the ideal TRAP markers to assess bone metabolism should determine the TRAP5b isoform by itself, since it has an osteoclastic origin, resulting from resorption activity, whereas the TRAP5a isoform is nonosteoclastic [24]. The occurrence of seven outliers (three in 6 months old, one in the 2 years and three in 8 years old group) in the determination of TRAP could be justified in this study by the marker being expressed in different tissues, such as muscles and heart, 
or pathological conditions. There are published studies in humans that correlated TRAP with leukemia and AIDS [25]. However, the present study used healthy animals and obtained normal values for the ovine species. In the present study, the values found are within the reported range of minimum value in adults and maximum values in juveniles $(0,14-5,9 \mathrm{U} / \mathrm{L})$ [11]. It is thus not possible to state which tissue was responsible for the occurrence of outliers and whether there was a pathological cause for these outliers. All TRAP variations can be explained by physiological or pathological changes as previously described.

This study presented a reasonable degree of correlation between $\mathrm{P}$ and $\mathrm{Ca}$, previously described in sheep as being involved in bone mineralization [26]. In rats, the increase of these serum minerals were essential for mineralization of bone tissue developed in vitro [27]. The degree of correlation present between ALP and $\mathrm{Ca}$ is possibly caused by the role of $\mathrm{Ca}$ in enzymatic reactions involving ALP, a correlation which has been previously described $[3,12]$.

With regard to the three groups of 3- to 5-year old sheep in different physiologic stages, only the pregnant group showed values that were considerably lower than the dry and lactation groups for ALP analyses. A similar increase of ALP throughout pregnancy has been previously described [28]. However, Liesegang et al. (2006) [29] used the BALP isoform and obtained a decrease of the marker during gestation. Therefore, when the animals become pregnant, there is a significant reduction of ALP, which then increases between gestation and lactation, and is slightly decreased in dry sheep [28]. In this study, the same marker variation was observed among the three described physiologic states, as has been previously described. However, during the analysis of TRAP, the lactating group showed lower values when compared to the dry ones. This could be due to the abrupt drop in bone resorption during the 2 to 3 months of lactation, with values going back to basal values in dry animals. Another greatly important factor would be that the maximum peak of TRAP would occur closer to parturition, as described [28].

\section{Conclusions}

This study provided information on the variation of two of the most used BTMs - ALP and TRAP, throughout the different stages of life and metabolic stages in sheep. These bone turnover markers variations can be entirely explained by known physiology, confirming that unexplained changes do not occur during the lifespan of sheep. This information may be a useful tool in clinical orthopedic research studies both in animal and veterinary sciences, as well as when using sheep as an animal model for translational studies for humans.

\section{Abbreviations}

ALP: Alkaline phosphatase.; BALP: Bone-specific isoform alkaline phosphatase.; BTMs: Bone turnover biomarkers.; Ca: Calcium; IQR: Interquartile range; Kg: Kilogram; Max: Maximum; Mg: Magnesium; Min: Minimum; P: Phosphorus; rpm: Revolutions per minute; TRAP5a: Tartrate-resistant acid phosphatase isoform 5a; TRAP5b: Tartrate-resistant acid phosphatase isoform 5b;

TRAP: Tartrate-resistant acid phosphatase

\section{Acknowledgements}

José Arthur de A. Camassa acknowledges the National Council for Scientific and Technological Development (CNPq - Brazil) for his PhD scholarship 202248/2015-1.

\section{Funding}

National Council for Scientific and Technological Development (CNPq - Brazil) PhD scholarship 202248/2015-1.

\section{Availability of data and materials}

The datasets generated during and/or analyzed during the current study are available from the corresponding author on reasonable request.

\section{Authors' contributions}

All authors of this paper have read and approved the final version of the manuscript submitted, they also agree to be accountable for all aspects of the work in ensuring that questions relating to the accuracy or integrity of any part of the work ate appropriately investigated and resolved and all of them have made substantive contributions to the work, namely: Substantially contributed to conception or design (JA, CC, CA, ND, IR). Contributed to acquisition, analysis, or interpretation of data (JA, CC, JP, MA, JT, IR). Drafted the manuscript (JA, CC, IR). Critically revised the manuscript for important intellectual content (JP, MA, JT, CA, ND, IR).

Ethics approval and consent to participate

Direcção-Geral de Veterinária, Portugal, License 0420/000/000/2009.

\section{Consent for publication}

Not applicable.

\section{Competing interests}

The authors declare that they have no competing interests.

\section{Publisher's Note}

Springer Nature remains neutral with regard to jurisdictional claims in published maps and institutional affiliations.

\section{Author details}

${ }^{1}$ Department of Veterinary Sciences, Agricultural and Veterinary Sciences School (ECAV), University of Trás-os-Montes and Alto Douro (UTAD), Quinta de Prados, P.O. Box 1013, 5001-801 Vila Real, Portugal. ${ }^{2}$ Federal Rural University of Pernambuco (UFRPE), R. Dom Manoel de Medeiros, s/n, Dois Irmãos, Recife, PE 52171-900, Brazil. ${ }^{3}$ CITAB - Centre for the Research and Technology of Agro-Environmental and Biological Sciences, UTAD, Vila Real, Portugal. ${ }^{4}$ Department of Animal Sciences, ECAV, UTAD, Vila Real, Portugal. ${ }^{5}$ CECAV - Centre for Animal Sciences and Veterinary Studies, UTAD, Vila Real, Portugal. ${ }^{6}$ CMEMS-UMinho, Department of Mechanical Engineering, University of Minho, Campus de Azurém, 4804-533 Guimarães, Portugal.

Received: 9 December 2016 Accepted: 9 August 2017

Published online: 15 August 2017

References

1. Allen MJ. Biochemical markers of bone metabolism in animals: uses and limitations. Vet Clin Pathol. 2003;32:101-13.

2. Baharuddin NA, Coates DE, Cullinan M, Seymour G, Duncan W. Localization of rank, rankl and osteoprotegerin during healing of surgically created periodontal defects in sheep. J Periodont Res. 2015;50:211-9.

3. Dias IR, Viegas CA, Azevedo JT, Costa EM, Lourenco P, Rodrigues A, Cabrita AS. Assessment of markers of bone formation under controlled environmental factors and their correlation with serum minerals in adult sheep as a model for orthopaedic research. Lab Anim. 2008;42:465-72. 
4. Cremers S, Garnero P, Seibel MJ. Biochemical markers of bone metabolism In: Bilezikian JP, Raisz LG, Martin TJ, editors. Bone biology. San Diego: Academic Press; 2008. p. 1857-81.

5. Millan JL. Alkaline Phosphatases: structure, substrate specificity and functional relatedness to other members of a large superfamily of enzymes. Purinergic Signal. 2006;2:335-41.

6. Masrour Roudsari J, Mahjoub S. Quantification and comparison of bone-specific alkaline phosphatase with two methods in normal and paget's specimens. Caspian J Intern Med. 2012;3:478-83.

7. Seibel MJ. Nutrition and molecular markers of bone remodelling. Curr Opin Clin Nutr Metab Care. 2002;5:525-31.

8. Schleicher I, Lips KS, Sommer U, Schappat I, Martin AP, Szalay G, Hartmman S, Schnettler R. Biphasic scaffolds for repair of deep osteochondral defects in a sheep model. J Surg Res. 2013;183:184-92.

9. Leeming DJ, Alexandersen P, Karsdal MA, Qvist P, Schaller S, Tanko LB. An update on biomarkers of bone turnover and their utility in biomedical research and clinical practice. Eur J Clin Pharmacol. 2006;62:781-92.

10. Halleen JM, Alatalo SL, Suominem H, Cheng S, Janckila AJ, Väänänen HK Tartrate-resistant acid phosphatase 5b: a novel serum marker of bone resorption. J Bone Miner Res. 2000;15:1337-45.

11. Seebeck $P$, Bail HJ, Exner $C$, Schell $H$, Michel $R$, Amthauer $H$, Bragulla $H$, Duda GN. Do serological tissue turnover markers represent callus formation during fracture healing? Bone. 2005;37:669-77.

12. Sousa C, Abreu H, Viegas C, Azevedo J, Reis R, Gomes ME, Dias I. Serum total and bone alkaline phosphatase and tartrate-resistant acid phosphatase activities for the assessment of bone fracture healing in dogs. Arq Bras Med Vet Zootec. 2011;63:1007-11.

13. O'Loughlin PF, Morr S, Bogunovic L, Kim AD, Park B, Lane JM. Selection and development of preclinical models in fracture-healing research. J Bone Joint Surg Am. 2008;90:79-84.

14. Reichert JC, Saifzadeh S, Wullschleger ME, Epari DR, Schutz MA, Duda GN, Schell H, van GM RH, Hutmacher DW. The challenge of establishing preclinical models for segmental bone defect research. Biomaterials. 2009; 30:2149-63.

15. Liesegang A, Sassi M-L, Risteli J. Diurnal variation in concentrations of various markers of bone metabolism in growing female goats and sheep. Anim Sci. 2003;77:197-203.

16. Arens D, Sigrist I, Alini M, Schawalder P, Schneider E, Egermann M. Seasonal changes in bone metabolism in sheep. Vet J. 2007;174:585-91.

17. Souberbielle JC, Cormier C, Kindermans C. Bone markers in clinical practice. Curr Opin Rheumatol. 1999;11:312-9.

18. Kahn CM. Reference guides: the Merck veterinary manual. 10th ed. New Jersey: Whitehouse Station; 2010

19. Chai J, Diao Q, Wang H, Tu Y, Tao X, Zhang N. Effects of weaning age on growth, nutrient digestibility and metabolism, and serum parameters in $\mathrm{Hu}$ lambs. Animal Nutrition. 2015;1:344-8.

20. Newman E, Turner AS, Wark JD. The potential of sheep for the study of osteopenia: current status and comparison with other animal models. Bone. 1995;16:277-84

21. Metson AJ, Saunders WMH. Seasonal variations in chemical composition D of pasture. New Zeal J Agr Res. 1978;21:341-53.

22. Clarke B. Normal bone anatomy and physiology. Clin J Am Soc Nephrol. 2008;3:S131-9.

23. Blumer MJ, Hausott B, Schwarzer C, Hayman AR, Stempel J, Fritsch H. Role of tartrate-resistant acid phosphatase (TRAP) in long bone development. Mech Dev. 2012;129:162-76.

24. Halleen JM, Ylipahkala H, Alatalo SL, Janckila AJ, Heikkinen JE, Suominen H, Cheng S, Väänänen HK. Serum tartrate-resistant acid phosphatase $5 b$, but not $5 \mathrm{a}$, correlates with other markers of bone turnover and bone mineral density. Calcif Tissue Int. 2002;1:20-5.

25. Hayman AR, Bune AJ, Bradley JR, Rashbass J, Cox TM. Osteoclastic tartrate-resistant acid phosphatase (Acp 5): its localization to dendritic cells and diverse murine tissues. J Histochem Cytochem. 2000:48:219-28.

26. Sousa CP, Azevedo JT, Silva AM, Viegas CA, Reis RL, Gomes ME, Dias IR. Serum total and bone alkaline phosphatase levels and their correlation with serum minerals over the lifespan of sheep. Acta Vet Hung. 2014; 62:205-14.

27. Chang YL, Stanford CM, Keller JC. Calcium and phosphate supplementation promotes bone cell mineralization: implications for hydroxyapatite (HA)-enhanced bone formation. J Biomed Mater Res. 2000;52:270-8.
28. Khatun A, Wani GM, Bhat JIA, Choudhury AR, Khan MZ. Biochemical indices in sheep during different stages of pregnancy. Asian J Anim Vet Adv. 2011; 6:175-81.

29. Liesegang A, Risteli J, Wanner M. The effects of first gestation and lactation on bone metabolism in dairy goats and milk sheep. Bone. 2006;38:794-802

\section{Submit your next manuscript to BioMed Central and we will help you at every step:}

- We accept pre-submission inquiries

- Our selector tool helps you to find the most relevant journal

- We provide round the clock customer support

- Convenient online submission

- Thorough peer review

- Inclusion in PubMed and all major indexing services

- Maximum visibility for your research

Submit your manuscript at www.biomedcentral.com/submit

) Biomed Central 